\title{
Metachronous bilateral breast metastases of a lung neuroendocrine tumor: A case report
}

\author{
MIE KOTAKE $^{1}$, HISAO IMAI ${ }^{1}$, RYOICHI ONOZATO ${ }^{2}$, ATSUSHI FUJITA ${ }^{2}$, TOMOMI FUJISAWA ${ }^{3}$, \\ YOSHIMASA NAKAZATO ${ }^{4}$, MISA IIJIMA $^{5}$, YASUHIRO YANAGITA ${ }^{3}$, TAKESHI HISADA ${ }^{6}$ and KOICHI MINATO ${ }^{1}$
}

\author{
Divisions of ${ }^{1}$ Respiratory Medicine, ${ }^{2}$ Thoracic Surgery and ${ }^{3}$ Breast Oncology, Gunma Prefectural Cancer Center, \\ Ota, Gunma 373-8550; ${ }^{4}$ Department of Diagnostic Pathology, Dokkyo Medical University, Mibu, \\ Tochigi 321-0293; ${ }^{5}$ Pathology and Clinical Laboratories, Gunma Prefectural Cancer Center, Ota, \\ Gunma 373-8550; ${ }^{6}$ Gunma University Graduate School of Health Science, Maebashi, Gunma 371-8514, Japan
}

Received February 18, 2019; Accepted June 2, 2020

DOI: $10.3892 / \mathrm{mco} .2020 .2123$

\begin{abstract}
Breast metastases of primary lung neuroendocrine tumors are rarely reported. The current report presents the case of a 41-year old female with no history of smoking who initially underwent surgery for a breast fibroadenoma, during which a neuroendocrine tumor of the right lung was detected via chest X-ray. The patient underwent surgery for the tumor and developed right breast nodules after adjuvant chemotherapy. Histological and immunohistochemical examinations of biopsies from these nodules indicated breast metastasis of the primary lung neuroendocrine tumor. The patient underwent mastectomy of the right breast but subsequently developed metastases in the left breast, for which local radiotherapy was administered. The observed metachronous bilateral breast metastases indicated that the contralateral breast should be considered during an investigation of metastasis.
\end{abstract}

\section{Introduction}

Lung cancer is the most common cause of cancer death worldwide (1). Localized stage of lung cancer represents approximately $15 \%$ of lung cancer (2). Estimated new case of non-small cell lung cancer (NSCLC) in the United states is approximately 22,800, with an estimated 13,500 death each year by NSCLC (2). After resection for early-stage NSCLC, $20 \%$ of patients developed recurrences (3). NSCLC patients with postoperative recurrence had poor prognosis. Survivals after recurrence were $13 \%$ at 5 years in patients who underwent resection for NSCLC (4). The most common sites of lung cancer metastases are the brain, bone, liver, and adrenal glands (5). Previous study showed that

Correspondence to: Dr Mie Kotake, Division of Respiratory Medicine, Gunma Prefectural Cancer Center, 617-1 Takahayashinishi, Ota, Gunma 373-8550, Japan

E-mail: m10702012@gunma-u.ac.jp

Key words: lung neuroendocrine tumor, metastatic cancer, breast metastases the first recurrent site was distant in $78 \%$ of patients and patients with distant recurrence had a shorter postrecurrent survival than those with local recurrence (6). There are only few reports that have demonstrated breast metastases of primary lung neuroendocrine tumors (7-10). Here, we report a case of a female patient who developed metachronous bilateral breast metastases of a lung neuroendocrine tumor.

\section{Case report}

A 41-year-old woman with no history of smoking underwent surgery for a breast fibroadenoma. An abnormal shadow was observed on a chest X-ray, and subsequent chest computed tomography (CT) revealed nodules on the right lung (Fig. 1). ${ }^{18}$ F-Fluorodeoxyglucose (FDG) positron emission tomography (PET)/CT revealed increased tracer uptake that was highly suggestive of lung cancer, with no evidence of metastasis. The patient underwent right lower and middle lobectomy, and immunohistochemistry revealed that the tumor cells were positive for transcription termination factor-1 (TTF-1), CD56, chromogranin A, and synaptophysin (Fig. 2). Additionally, 25.7\% of the tumor cells expressed the proliferation marker Ki67. A pathological analysis led to a diagnosis of neuroendocrine tumor.

A regular medical follow-up of the surgical outcomes for breast fibroadenoma revealed nodules in the right breast 3 months after adjuvant chemotherapy (Fig. 3), which were subsequently biopsied. Histological analyses of hematoxylin and eosin (H\&E)-stained, paraffin-embedded biopsy sections indicated carcinoma, and positive immunohistochemical staining for CD56, chromogranin A, and synaptophysin confirmed a neuroendocrine origin (Fig. 2). Accordingly, a diagnosis of breast metastasis of primary lung neuroendocrine tumor was made based on cytological and immunohistochemical similarities between the primary and metastatic lesions. The patient underwent mastectomy of the right breast after ${ }^{18} \mathrm{~F}$-FDG-PET/CT revealed no areas of increased tracer uptake. Subsequently, she developed metastases in the left breast, lung, lymph node, and peritoneum at 2 months post-mastectomy (Fig. 4). Systemic chemotherapy and local radiotherapy to the left breast were administered. The patient remained alive 6 months later, with no evidence of a bilateral breast recurrence. 


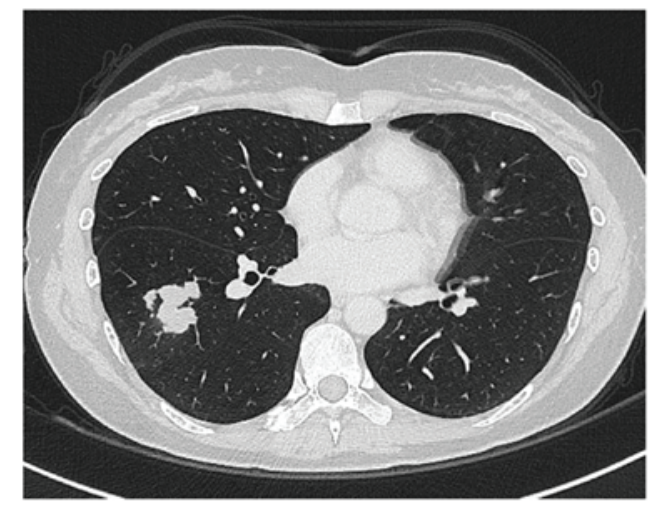

Figure 1. Chest computed tomography revealed nodules on the right lung, leading to a diagnosis of primary lung cancer.
A Hematoxylin and eosin staining

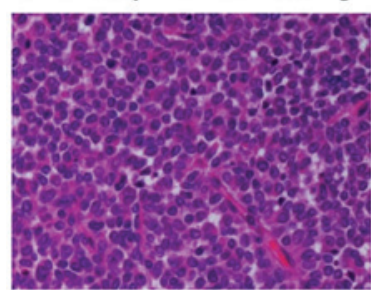

C CD56

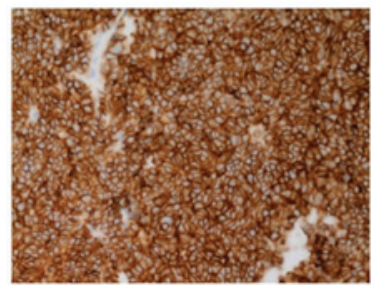

E Synaptophysin

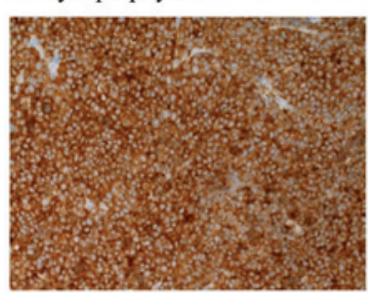

B Hematoxylin and eosin staining

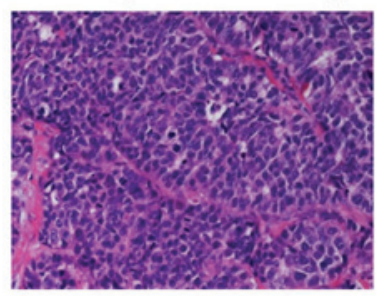

D CD56

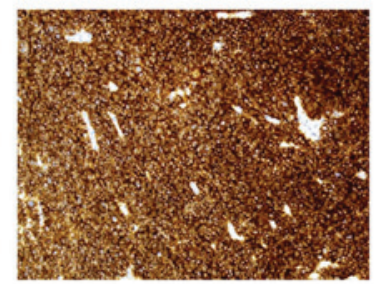

F Synaptophysin

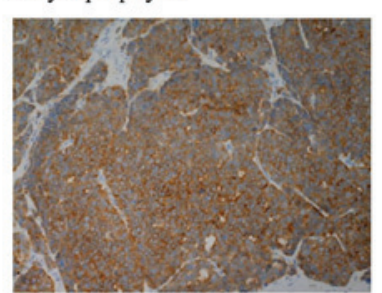

Figure 2. Photomicrographs of tumor sections. (A) Hematoxylin and eosin staining of the surgically excised lung lesion (magnification, $\mathrm{x} 400$ ). (C) Immunohistochemistry of the tumor cells revealed CD56 (magnification, x400) and (E) synaptophysin positivity (magnification, x200). (B) Hematoxylin and eosin staining of a biopsy specimen from the right breast (magnification, x100). (D) Immunohistochemistry also revealed tumor cells that were positive for CD56 (magnification, x200) and (F) synaptophysin (magnification, x100).

\section{Discussion}

Breast metastasis of lung cancer is rarely reported. Particularly, a few reports have described breast metastasis from lung neuroendocrine tumors, which account for approximately $3 \%$ of lung cancers in surgical series (7-11). Overall, breast metastases of all extramammary malignancies are very rare, accounting for $0.4-1.3 \%$ of all mammary malignancies $(12,13)$. These generally arise from primary hematological malignancies, melanoma, rhabdomyosarcoma, lung tumors, renal cell carcinoma, thyroid

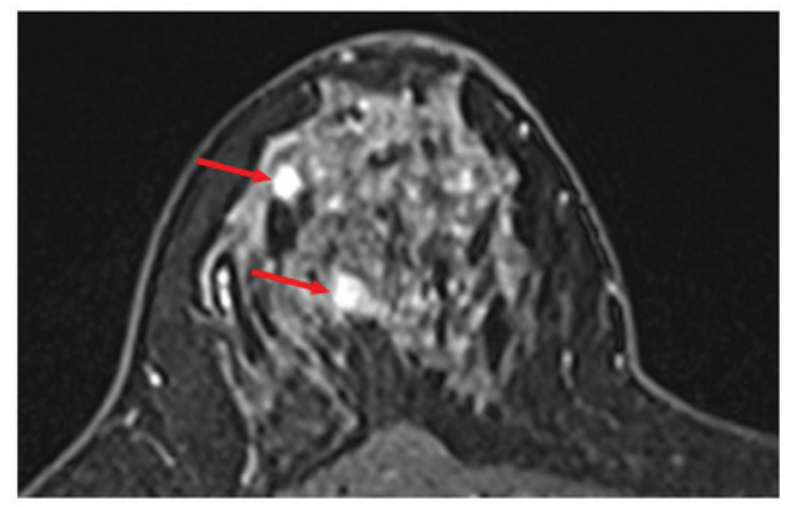

Figure 3. Magnetic resonance imaging revealed nodules (red arrows) in the right breast.

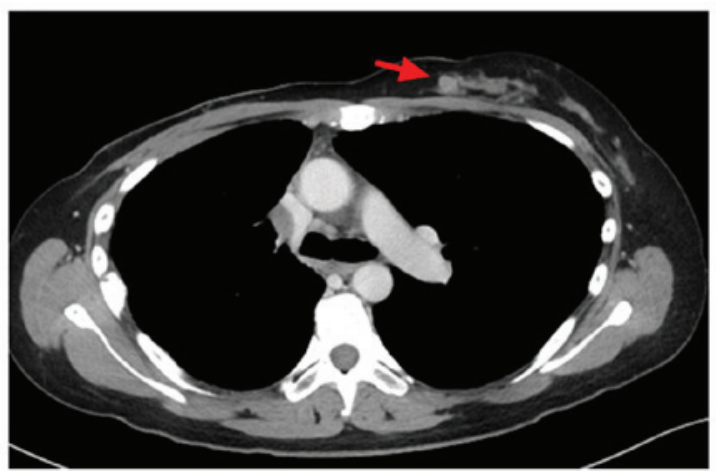

Figure 4. Chest computed tomography revealed nodules (red arrows) in the left breast.

and cervical carcinomas, intestinal carcinoid, epidermoid carcinoma of the head and neck, and leiomyosarcoma $(12,13)$.

Previous reports have demonstrated the benefits of local therapy for a subset of patients with stage IV non-small cell lung cancer and a small number of metastases $(14,15)$. Vaughan et al described three cases of breast metastases of neuroendocrine tumors of the lung, of which two were treated with surgery. One patient developed a breast metastasis 38 months after her original diagnosis, for which she underwent a lumpectomy and remained free of a breast recurrence 7 months later. The second patient presented with a breast metastasis 8 months after her original diagnosis and underwent an excisional biopsy. She subsequently developed another breast metastasis 4 months after the first excision and underwent radiation treatment (10). The patient in our case achieved good local control with a right mastectomy, but subsequently developed metastases in the left breast. However, she maintained good local control of the left-sided breast nodules after radiation therapy.

A search of the PubMed database between 2007 and 2017 identified 13 cases of breast metastases from neuroendocrine tumors of the lung (Table I). Despite the rarity of this condition, the possibility of metastasis to the breast from a lung neuroendocrine tumor should be considered in the differential diagnosis of a primary mammary carcinoma in patients postoperatively discovered to have a breast lesion. One of 13 patients had bilateral breast metastases during the initial diagnostic evaluation (Table I). This finding and our observa- 
Table I. Characteristics of previously reported cases of breast metastases from lung neuroendocrine tumors.

\begin{tabular}{|c|c|c|c|c|c|c|c|}
\hline Patient no. & $\begin{array}{c}\text { Age, } \\
\text { years/sex }\end{array}$ & $\begin{array}{l}\text { Interval, from } \\
\text { NET diagnosis } \\
\text { to breast tumor } \\
\text { (months) }\end{array}$ & $\begin{array}{l}\text { Vital } \\
\text { status }\end{array}$ & $\begin{array}{l}\text { Secondary } \\
\text { survival } \\
\text { (months) }^{\mathrm{a}}\end{array}$ & $\begin{array}{c}\text { Breast } \\
\text { laterality }\end{array}$ & $\begin{array}{c}\text { Breast } \\
\text { surgery/ } \\
\text { radiotherapy }\end{array}$ & Chemotherapy \\
\hline $1(9)$ & $44 / \mathrm{F}$ & 0 & NR & NR & NR & Mastectomy & NR \\
\hline $2(9)$ & $60 / \mathrm{F}$ & 22 & NR & NR & NR & Lumpectomy & NR \\
\hline $3(9)$ & $44 / F$ & 37 & NR & NR & NR & Lumpectomy & NR \\
\hline $4(9)$ & $28 / \mathrm{F}$ & 87 & NR & NR & NR & Lumpectomy & NR \\
\hline $5(9)$ & $42 / \mathrm{F}$ & 69 & NR & NR & NR & Lumpectomy & NR \\
\hline $6(9)$ & $62 / \mathrm{F}$ & 20 & NR & NR & NR & Lumpectomy & NR \\
\hline $7(9)$ & $45 / F$ & 36 & NR & NR & NR & Not performed & NR \\
\hline $8(9)$ & $72 / \mathrm{F}$ & 20 & NR & NR & NR & Not performed & NR \\
\hline $9(10)$ & $30 / \mathrm{F}$ & 38 & Alive & 7 & Left & Lumpectomy & NR \\
\hline $10(10)$ & $35 / \mathrm{F}$ & 0 & Alive & 9 & Bilateral & Not performed & NR \\
\hline $11(10)$ & $28 / \mathrm{F}$ & 8 & Dead & 17 & Right & $\begin{array}{l}\text { Lumpectomy, } \\
\text { radiotherapy }\end{array}$ & NR \\
\hline $12(8)$ & $49 / \mathrm{F}$ & 6 & Dead & 7 & Left & Radiotherapy & Not performed \\
\hline $13(7)$ & $59 / \mathrm{F}$ & 0 & Dead & NR & Right & Not performed & $\begin{array}{l}\text { Cisplatin + etoposide, } \\
\text { topotecan }\end{array}$ \\
\hline $\begin{array}{l}\text { The current } \\
\text { case }\end{array}$ & $41 / \mathrm{F}$ & 12 & Alive & 18 & Bilateral & $\begin{array}{l}\text { Mastectomy, } \\
\text { radiotherapy }\end{array}$ & Performed \\
\hline
\end{tabular}

${ }^{a}$ Time interval between the diagnosis of breast metastasis and death or study follow-up. NR, not reported; F, female.

tion of metachronous bilateral breast metastases in the present case leads us to suggest that the contralateral breast should be considered in an investigation of metastasis.

In summary, we report herein a rare case of a patient with metachronous bilateral breast metastases of a primary lung neuroendocrine tumor. The present case suggests that local therapy provides good control of these metastatic lesions.

\section{Acknowledgements}

The authors would like to thank Dr Takeshi Kawakami and Dr Hiroyuki Horikoshi (Division of Diagnostic Radiology of Gunma Prefectural Cancer Center) for helping with figure preparation. The authors would also like to thank Dr Sakae Fujimoto (Division of Respiratory Medicine of Gunma Prefectural Cancer Center) for his assistance in preparing this manuscript.

\section{Funding}

No funding was received.

\section{Availability of data and materials}

All data generated or analyzed during the present study are included in this published article.

\section{Authors' contributions}

MK, HI and KM designed the current study. MK, HI, RO, AF, TF, YY, YN, MI and KM acquired and analyzed the data. YN and MI performed histological examinations of the tumor specimens. MK and HI drafted the manuscript and constructed the figures. TH advised the study and analyzed the data. All the authors read and approved the final version of the manuscript.

\section{Ethics approval and consent to participate}

Not applicable.

\section{Patient consent for publication}

Written informed consent was obtained from the patient for publication.

\section{Competing interests}

The authors declare that they have no competing interests.

\section{References}

1. Ferlay J, Soerjomataran I, Dikshit R, Eser S, Mathers C, Rebelo M, Parkin DM, Forman D and Bray F: Cancer incidence and mortality worldwide, sources, methods and major patterns in GLOBOCAN 2012. Int J Cancer 136: E359-E386, 2015.

2. Siegel RL, Miller KD and Jemal A: Cancer statistics, 2020. CA Cancer J Clin 70: 7-30. 2020

3. Lou F, Huang J, Sima CS, Dycoco J, Rusch V and Bach PB: Patterns of recurrence and second primary lung cancer in earlystage lung cancer survivors followed with routine computed tomography surveillance. J Thorac Cardiovasc Surg 145: 75-81, 2013 
4. Sekihara K, Hishida T, Yoshida J, Oki T, Omori T, Katsumata S, Ueda T, Miyoshi T, Goto M, Nakasone S, Ichikawa T, et al: Long-term survival outcome after postoperative recurrence of non-small-cell lung cancer: who is 'cured' from postoperative recurrence? Eur J Cardiothorac Surg 52: 522-528, 2017

5. Quint LE, Tummala S, Brisson LJ, Francis IR, Krupnick AS, Kazerooni EA, Iannettoni MD, Whyte RI and Orringer MB: Distribution of distant metastasis from newly diagnosed non-small cell lung cancer. Ann Thorac Surg 62: 246-250, 1996.

6. Ichinose Y, Yano T, Yokoyama H, Inoue T, Asoh H, Tayama K and Takanashi N: Postrecurrent survival of patients with nonsmall-cell lung cancer undergoing a complete resection. J Thorac Cardiovasc Surg 108: 158-61, 1994.

7. Papa A, Rossi L, Verrico M, Di Cristofano C, Moretti V, Strudel M, Zoratto F, Minozzi M and Tomao S: Breast metastasis and lung large-cell neuroendocrine carcinoma: First clinical observation. Clin Respir J 11: 574-578, 2017.

8. Rimner A and Rosenzweig KE: Palliative radiation for lung cancer metastasis to the breast: Two case reports. J Thorac Oncol 2: 1133-1135, 2007.

9. Crona J, Granberg D, Norlén O, Wärnberg F, Stålberg P, Hellman P and Björklund P: Metastases from neuroendocrine tumors to the breast are more common than previously thought. A diagnostic pitfall? World J Surg 37: 1701-1706, 2013.

10. Vaughan A, Dietz JR, Moley JF, Debenedetti MK, Aft RL, Gillanders WE, Eberlein TJ, Ritter J and Margenthaler JA: Metastatic disease to the breast: The Washington university experience. World J Surg Oncol 5: 74, 2007.

11. Travis WD: Pathology and diagnosis of neuroendocrine tumors: Lung neuroendocrine. Thorac Surg Clin 24: 257-266, 2014.
12. Vizcaíno I, Torregrosa A, Higueras V, Morote V, Cremades A, Torres V, Olmos S and Molins C: Metastasis to the breast from extramammary malignancies: A report of four cases and a review of literature. Eur Radiol 11: 1659-1665, 2001.

13. Toombs BD and Kalisher L: Metastatic disease to the breast: Clinical, pathologic, and radiographic features. AJR Am J Roentgenol 129: 673-676, 1977.

14. Gomez DR, Blumenschein GR Jr, Lee JJ, Hernandez M, Ye R, Camidge DR, Doebele RC, Skoulidis F, Gaspar LE, Gibbons DL, et al: Local consolidative therapy versus maintenance therapy or observation for patients with oligometastatic non-small-cell lung cancer without progression after first-line systemic therapy: A multicentre, randomised, controlled, phase 2 study. Lancet Oncol 17: 1672-1682, 2016.

15. Matsuguma $H$, Nakahara R, Wakamatsu I, Kishikawa $T$, Sugiyama T, Nakamura Y, Kasai T, Kamiyama Y, Hoshi N, Inoue $\mathrm{K}$, et al: Definitive local therapy for oligo-recurrence in patients with completely resected non-small cell lung cancer. Am J Clin Oncol 43: 210-217, 2020. 